\title{
Electrochemical Study of Metallic Foams Ti-Ta-Sn Through SEM
}

Abraham Mejia ${ }^{1}$, Luis Bejar ${ }^{1}$, Engelbert Huape ${ }^{1}$, Luis Bejar-Vega ${ }^{1}$, Claudio Aguilar ${ }^{2}$, Carolina Parra ${ }^{2}$ and Ismeli Alfonso 3

${ }^{1}$ Universidad Michoacana de San Nicolás de Hidalgo, Morelia, Michoacan de Ocampo, Mexico, ${ }^{2}$ Universidad Técnica Federico Santa Maria, Valparaiso, Valparaiso, Chile, ${ }^{3}$ UNAM, Morelia, Michoacan de Ocampo, Mexico

Commercially pure titanium and metallic alloys of $\mathrm{Ta}, \mathrm{Sn}, \mathrm{Co}, \mathrm{Cr}$, Ni with titanium base are some of the most used materials for dental implants due to their excellent mechanical properties, corrosion resistance and good osseointegration, which improve when the surfaces are rough [1-2]. The Corrosion in biomaterials is very common, especially in prostheses with salivary solution, due to the screening and wear of the material in this type of applications [3]. By increasing the temperature the diffusion of oxygen in the sample is accelerated which causes the corrosion rate to increase so that the alloyed material is affected by embrittlement even through the layers of passivation. To change its titanic allotropic phase to the $\beta$ phase, concerning the temperature used in the manufacturing process which was also influenced by the elements of Ta as an Isomorphic stabilizer $\beta$ and as a neutral element the Sn. The Ti-Ta-Sn metal powders were mixed for 30 minutes, compacted at $430 \mathrm{Mpa}$ to obtain the products in green and sintered at a temperature of $25-1200^{\circ} \mathrm{C}$. In this work, the Ti-Ta-Sn alloy in salivary solution with $\mathrm{pH} 6.8$ at $37^{\circ} \mathrm{C}$ in a three-electrode electrochemical cell was evaluated. The reference electrode (calomel), the work electrode (samples Ti-Ta-Sn) and the Auxiliary electrode (Graphite), the study was carried out for 24 hours with an open circuit potential, $+1250 \mathrm{mV}$ at $-1250 \mathrm{mV}$ and polarization resistance $\pm 10 \mathrm{mV}$. The micrographs of the Ti-Ta-Sn alloy by (MEB) obtained by electrodispersed electrons in high current $1 \mu \mathrm{A}$, $20 \mathrm{Kv}$, in high vacuum. The figure 1 shows the morphology in the micrograph before performing the corrosion test where it can be observed that there was a homogeneous mixture with shades in dark and light gray, the brightest are metallic elements with a higher density. In Figure 2, after performing the corrosion study, a change in surface and morphology, in general, is shown the material exhibits degradation by dissolution. We can conclude that the Ti-Ta-Sn alloy obtained a low corrosion current density, Sample behavior shows good corrosion resistance behavior, which is why it is considered an excellent material for biomedical applications. 


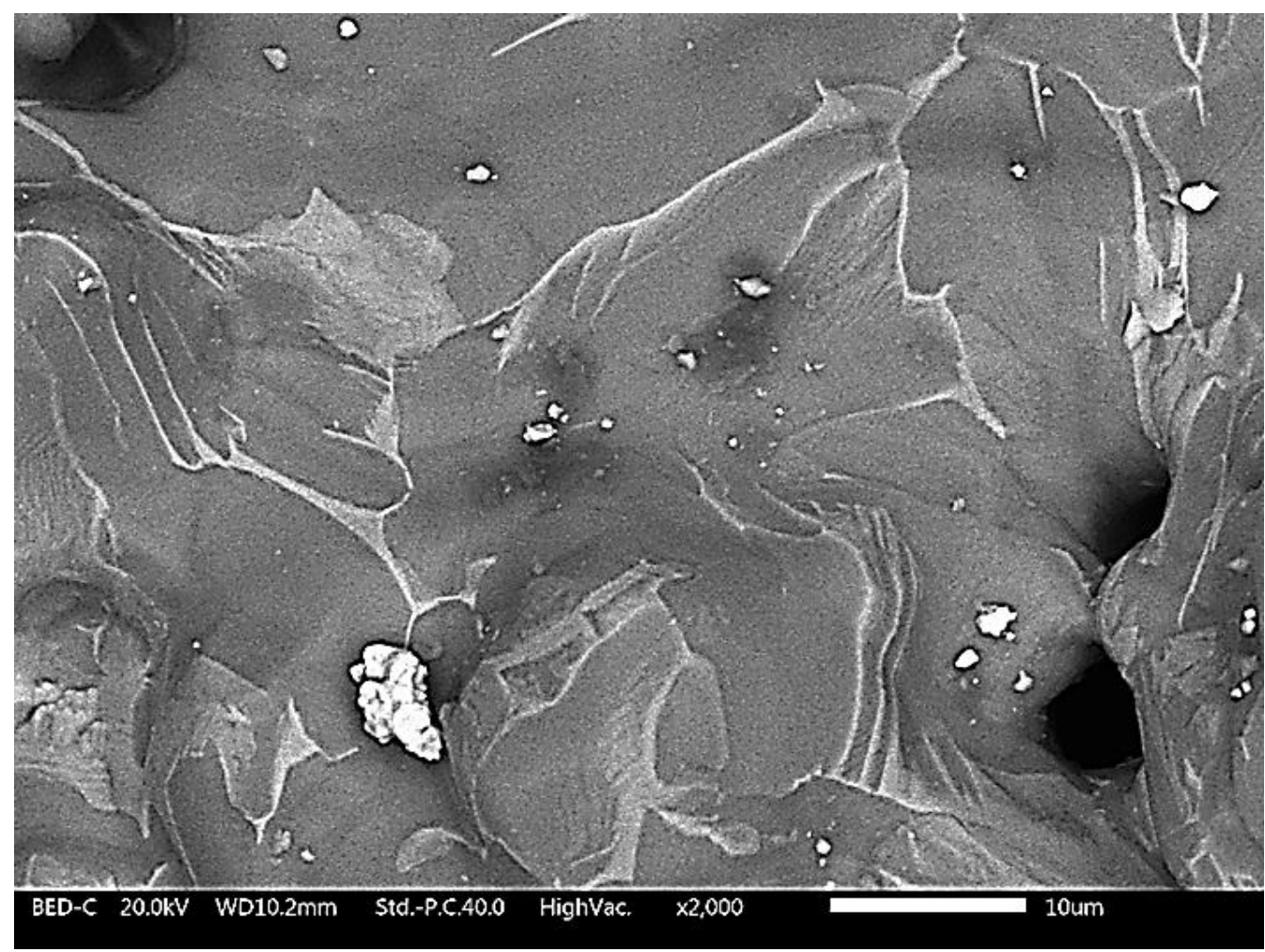

Figure 1. Surface morphology before the corrosion study Alloy Ti-Ta-Sn.

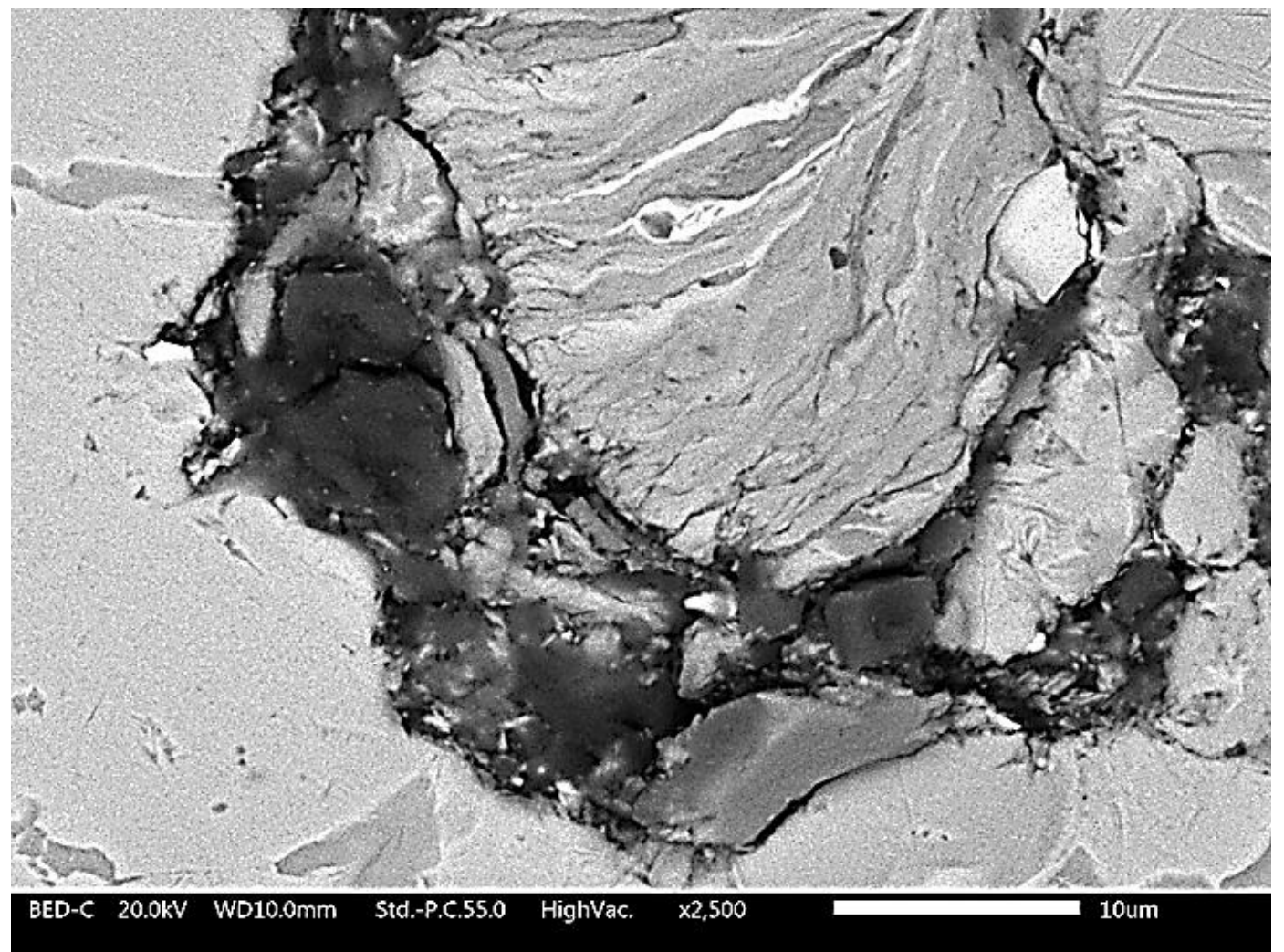

Figure 2. The microstructure of Ti-Ta-Sn Alloy morphology, after of the corrosion study. 


\section{References}

[1]. Mohit Sharma, A.V. Ramesh Kumar, Nirbhay Singh, Nidhi Adya, and Bobin Saluja "Electrochemical Corrosion Behavior of Dental/Implant Alloys in Artificial Saliva" Journal of Materials Engineering and Performance Volume 17(5), (2008) 695-701.

[2]. Conrado Aparicio, F. Javier Gil, Carlos Fonseca, Mario Barbosa, Josep Anton Planell. “Corrosion behaviour of commercially pure titanium shot blasted with different materials and sizes of shot particles for dental implant applications" Biomaterials 24 (2003) 263-273.

[3] Norma Terumi Kadowaki, Gustavo Aristides Santana Martinez, Alain Robin. "Electrochemical Behavior of Three CP Titanium Dental Implants in Artificial Saliva” Materials Research, Vol. 12, No. 3, 363-366, 2009. 